Western University

Scholarship@Western

$4-1-2012$

Quantitative pulmonary imaging using computed tomography and magnetic resonance imaging

George R Washko

Grace Parraga

Harvey 0 Coxson

Follow this and additional works at: https://ir.lib.uwo.ca/biophysicspub

Part of the Medical Biophysics Commons

Citation of this paper:

Washko, George R; Parraga, Grace; and Coxson, Harvey O, "Quantitative pulmonary imaging using computed tomography and magnetic resonance imaging" (2012). Medical Biophysics Publications. 148.

https://ir.lib.uwo.ca/biophysicspub/148 


\title{
Quantitative pulmonary imaging using computed tomography and magnetic resonance imaging
}

\author{
George R. WASHKO, ${ }^{1}$ Grace PARRAGA ${ }^{2}$ AND harvey O. COXSON ${ }^{3}$
}

\begin{abstract}
${ }^{1}$ Department of Medicine, Division of Pulmonary and Critical Care Medicine, Brigham and Women's Hospital, Boston, Massachusetts, USA, ${ }^{2}$ Imaging Research Laboratories, Robarts Research Institute and Departments of Medical Biophysics, Medical Imaging, The University of Western Ontario, London, Ontario, and ${ }^{3}$ University of British Columbia Department of Radiology, UBC James Hogg Research Centre, Vancouver General Hospital, Institute for Heart and Lung Health, University of British Columbia, Vancouver, British Columbia, Canada
\end{abstract}

\begin{abstract}
Measurements of lung function, including spirometry and body plethesmography, are easy to perform and are the current clinical standard for assessing disease severity. However, these lung functional techniques do not adequately explain the observed variability in clinical manifestations of disease and offer little insight into the relationship of lung structure and function. Lung imaging and the image-based assessment of lung
\end{abstract}

The Authors: George R. Washko, MD M.S. is Assistant Professor of Medicine, Harvard Medical School and a Pulmonary and Critical Care physician at Brigham and Women's Hospital with an interest in the application of quantitative image analysis to clinical investigation. Grace Parraga, PhD is Associate Professor of Medical Imaging, Medical Biophysics, and Biomedical Engineering at The University of Western Ontario and a scientist at the Imaging Research Laboratories, Robarts Research Institute with an interest in developing tools for quantitative pulmonary imaging. Harvey O. Coxson, PhD is Associate Professor of Radiology at the University of British Columbia and Investigator at the UBC James Hogg Research Centre with an interest in quantitative imaging of the lung with applications to understanding the pathogenesis of chronic obstructive pulmonary disease.

Correspondence: Harvey O. Coxson, UBC Department of Radiology, Vancouver General Hospital, 855 West 12th Ave, Room CP-G22A, Vancouver, BC V5Z 1M9, Canada. Email: harvey.coxson@vch.ca

Conflict of interest statement: GRW and GP have no conflict related to the content of this manuscript. HOC has received an honorarium for serving on the steering committee for the ECLIPSE project for GSK; was the co-investigator on two multicenter studies sponsored by GSK and has received travel expenses to attend meetings related to the project; has a contract service agreement with GSK to quantify the computed tomography scans in subjects with chronic obstructive pulmonary disease and a service agreement with Spiration Inc to measure changes in lung volume in subjects with severe emphysema; has received a fee for speaking at a conference and related travel expenses from AstraZeneca (Australia). There is no financial relationship between any industry and the current study.

Received 25 October 2011; invited to revise 5 November 2011; revised 8 November 2011; accepted 9 November 2011. disease has matured to the extent that it is common for clinical, epidemiologic and genetic investigation to have a component dedicated to image analysis. There are several exciting imaging modalities currently being used for the non-invasive study of lung anatomy and function. In this review, we will focus on two of them; $\mathrm{X}$-ray computed tomography and magnetic resonance imaging. Following a brief introduction of each method, we detail some of the most recent work being done to characterize smoking-related lung disease and the clinical applications of such knowledge.

Key words: asthma, chronic obstructive pulmonary disease, emphysema, radiology and other imaging.

\section{INTRODUCTION}

Disease-related alterations in lung structure are responsible for much of the functional limitations observed in a variety of conditions such as asthma, chronic obstructive pulmonary disease (COPD) and interstitial lung disease. These structural changes are the result of destruction or remodelling of the lung parenchyma and airway wall. Remodelling is defined as changes in the composition, content and organization of the cellular and molecular constituents of the lung tissue and contributes directly to changes in lung elasticity and compliance as well as airway narrowing. The gold standard for the detection and quantification of lung remodelling has always been histological examination. Such studies have provided valuable information on the processes and consequences of lung remodelling but are limited because they require access to surgical or autopsy samples and are necessarily cross-sectional in design. Therefore, noninvasive methods are required to further investigate the pathogenesis of lung disease, to assess changes over time and to allow the assessment of new therapeutic interventions designed to attenuate or reverse these structural changes. Imaging techniques such as 
Figure 1 Gross pathology and computed tomography imaging. Excised gross lung specimen (a) and matched computed tomography (CT) section of the same specimen (b) from a subject undergoing lung transplantation for severe emphysema. These images clearly show the severity of the emphysema (arrow heads) and some airways cut in cross section (arrows). These images also illustrate that CT can produce images that are very similar to the actual lung seen in the gross specimen. (Images provide courtesy of Dr John McDonough, UBC James Hogg Research Centre).

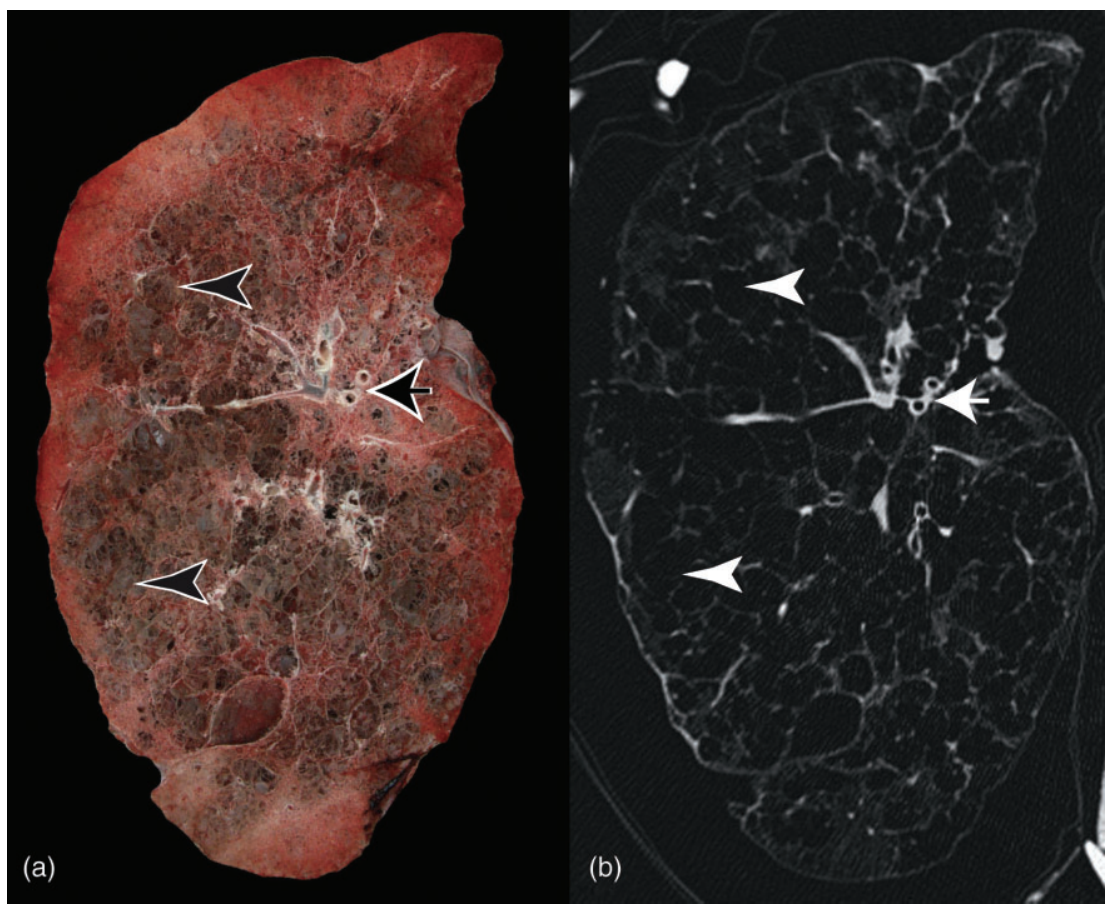

X-ray computed tomography (CT) and magnetic resonance imaging (MRI) allow for an in vivo assessment of lung parenchyma as well as airway wall thickness that is comparable to gross histological examination (Fig. 1). However, the information that can be obtained from CT lacks the detail of what can be obtained from histology, and there are increasing concerns over the health risks related to the ionizing radiation necessary to acquire such images. Furthermore, MRI, while not limited by radiation risks, has its own limitations in terms of tissue and spatial resolution. However, these imaging techniques are providing new information about lung structure and function that have not been available before. The aim of the current paper is to review the use of CT and MRI in the investigation of lung structure and function in health and disease, outlining the strengths and weakness of both techniques.

\section{CT OF LUNG PARENCHYMA}

\section{Emphysema}

Smoking-related destruction of the lung parenchyma is typically thought to manifest as emphysema and is usually described as being centrilobular, panlobular or paraseptal. Gough and Wentworth, subsequently modified by Thurlbeck, described methods to quantify the extent of the tissue destruction using fixed slices of resected lungs. Obviously, while incredibly important, assessments of lung destruction from resected or post-mortem specimens do not provide data that can help an individual patient. Therefore, attention turned to roentologic studies of the lungs of smokers which identified several cardinal signs for the presence of emphysema such as increased lucency of the lung fields, narrowing of the cardiac silhouette and pruning of the peripheral vasculature. Such findings are sensitive but lack the specificity required for large scale clinical and research applications.

With the introduction of CT into the medicine in the late 1970s, it became possible to visualize and display lung structure in vivo in $3 \mathrm{D}$ with tissue structures resolved and appearing very similar to gross pathology images. Furthermore, because the CT image is really a densitometric map of the lung, it is ideally suited to quantitative assessments of emphysema. By comparing the frequency distribution of the apparent X-ray attenuation values to the extent of emphysema seen on gross pathology, or the histologically measured surface area of the lung, early investigators have found that CT could be used to quantify emphysema. ${ }^{1-4}$ These studies showed that by either applying a threshold cut-off of X-ray attenuation values, originally termed Density Mask Analysis, the extent of emphysema (densities less than a specific HU threshold) could be quantified (Fig. 2).$^{3-5}$ A second approach, developed at the same time, has become known as the percentile technique. Using this technique, the investigator chooses a point on the percentage scale, that is, 15 th percentile, where the cumulative percentage of the lung voxels are less than this cut-off (lowest 15th percentile), and the corresponding X-ray attenuation value (in $\mathrm{HU}$ ) at that point is determined (Fig. 2b). Early studies showed that the lowest 5 th percentile value correlated with the extent of emphysema ${ }^{1}$ and surface area to volume ratio, ${ }^{2}$ while recent studies show that the 15 th percentile value serves as a measurement of lung destruction. ${ }^{6,7}$ These two densitometric analyses of the lung parenchyma have become 


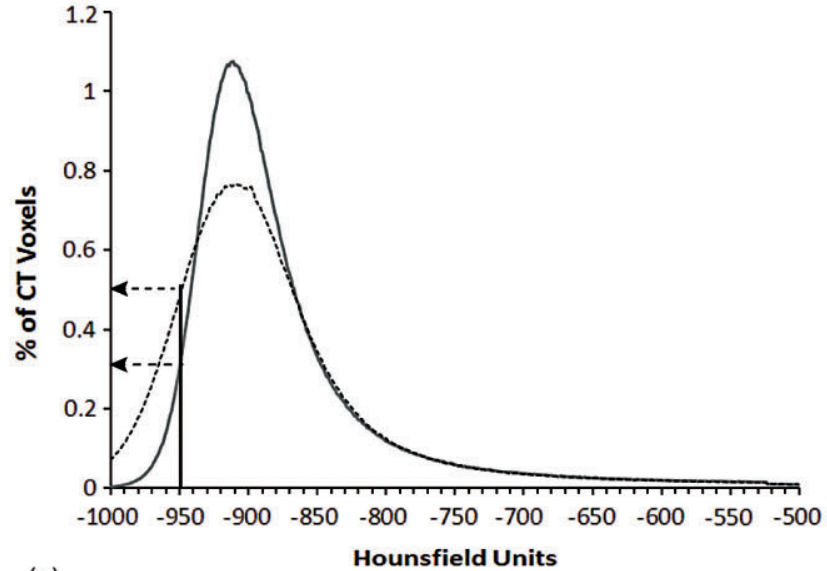

(a)

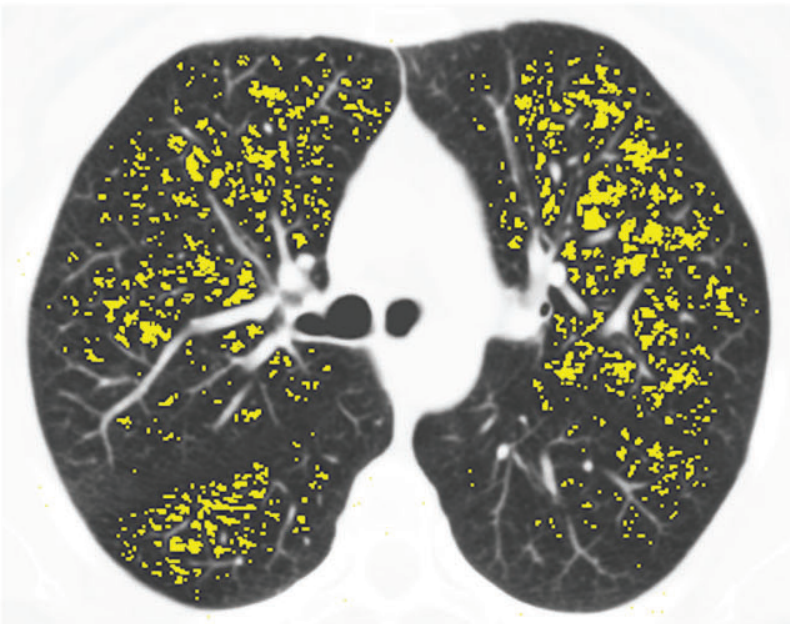

(c)
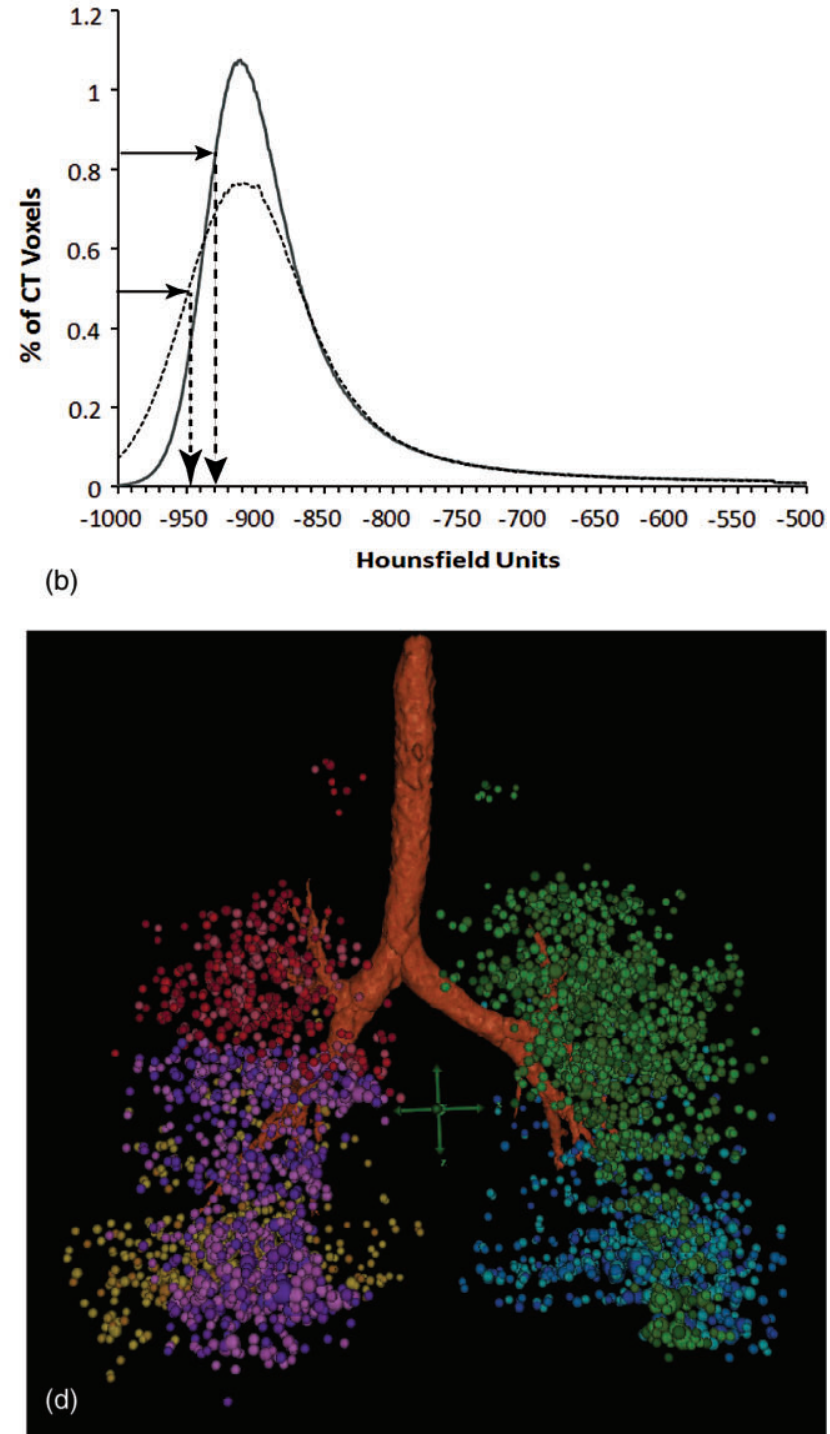

Figure 2 Quantitative computed tomography measurements of emphysema. These images illustrate the use of the threshold and percentile techniques to quantify the extent of emphysema. The apparent X-ray attenuation values are plotted as frequency distribution ( $a$ and $b$ ) and a shift in this distribution demonstrates a change in the air to tissue ratio within the lung. Panel (a) shows the threshold technique where a pre-defined threshold of HU (i.e. $-950 \mathrm{HU}$ ) is chosen, and the percentage of lung less than this value is calculated. There is a greater percentage of the lung voxels beyond the threshold in the dashed line subject than subject represented by the solid line. Similarly, the percentile technique is illustrated in (b) where a certain percentile point (i.e. lowest 15th percentile) is chosen, and the HU values for that percentile calculated. The HU value of the lowest 15th percentile is more negative (less dense) in the dashed line subject than the solid line subject. Image (c) shows the CT voxels less than $-950 \mathrm{HU}$ in a transverse image, and (d) shows how these low attenuation values are clustered using a three-dimensional reconstruction of the lung. CT, computed tomography.

the cornerstone of radiological characterization of lung disease in smokers.

There have been numerous studies in the literature that show that densitometric analysis is predictive of clinically significant metrics such as lung function. ${ }^{8-13}$ However, longitudinal applications of these techniques are more limited studies such as those by Dirksen, and co-investigators show that the use of CT will provide an analysis of change in lung density over time that is more sensitive to intervention than the usual analysis of change in lung function forced expi- ratory volume in $1 \mathrm{~s}\left(\mathrm{FEV}_{1}\right) .^{6}$ In fact, Dirksen and colleagues have shown that the 15th percentile technique is able to show differential changes in lung densitometry following pharmacologic intervention with either alpha-1 antitrypsin augmentation ${ }^{7}$ or treatment with steroids. ${ }^{14}$ They have also shown that following smoking cessation, there is a decrease in lung density, which on the surface appears to be the opposite of the expected result, which they attribute to a generalized loss of tissue density due to some combination of reduced inflammatory response or 
reduction in other dense objects in the lung like soot and tar. ${ }^{15}$ In another study Yuan et al. found that if the lung density was expressed as a percentage of maximal lung inflation, defined as predicted total lung capacity divided by predicted lung weight, the subjects with the greatest extent of over inflated lung also showed the greatest decline in lung function over time. ${ }^{16}$ These studies suggest that not only can CT densitometry be used to follow disease pathogenesis but that it can be used to monitor the response to therapy with a greater level of precision than standard lung functional measurements.

However, an important caveat to these methods is that the appropriate HU threshold used to delineate emphysematous from non-emphysematous tissue is subject to the image acquisition and reconstruction parameters. ${ }^{17-19}$ Furthermore, the lung volume at which the CT scan is acquired will also play a large role in the lung density. For these reasons a working group of the Alpha-1 Foundation recommended that while either the threshold technique or the percentile technique can be used in cross-sectional studies, the percentile technique, corrected for lung volume, is the best metric to be used in longitudinal studies. ${ }^{20}$ However, both of these techniques are currently used, and while the data for the percentile technique is very strong, the threshold technique provides a value that is often more meaningful in terms of understanding how much emphysema is present in the lung and allows localization and visualization of the low attenuation regions (Fig. 2).

While densitometric analysis of the lung may provide global, regional and lobar specific measures of emphysema on CT scan, a major limitation is its relative inability to differentiate emphysema subtype (centrilobular, panlobular, etc.). In an effort to address this, the community of radiologic and computer scientists has focused on developing techniques that may objectively identify emphysema type and distribution. These are based largely on patterns of local features in the secondary pulmonary lobule and are often referred to as textural analysis.

Texture analysis of the lung involves the selection of a discrete region of interest within the lung field and then assessing several parameters in this constrained region such as density and the patterns of changes in density. The simplest textural approach is the fractal, or cluster analysis, first used by Mishima. ${ }^{21}$ This technique examines low attenuating voxels identified using a threshold technique and quantifies them according to how many are connected, or clustered, together. This approach has been applied to CT data acquired in clinical investigations such as those involving lung volume reduction surgery, ${ }^{22,23}$ and despite there being a weak correlation to histopathology, ${ }^{24}$ it appears to more closely approximate a visual analysis performed by a radiologist than standard densitometry. ${ }^{25}$ More complex techniques have also been developed and several groups of investigators have demonstrated that this technique could accurately identify disease type (using visual analysis as a gold standard) and provide more robust measures of lung disease for correlation in clinical investigation. ${ }^{26-29}$ Indeed, Xu et al. demonstrated that such a technique could provide information that surpassed that provided by visual inspection. ${ }^{30}$ While the sensitivity of textural analysis is potentially superior to visual inspection, it is computationally costly, and until a more parsimonious approach to tissue classification is developed, it is limited to smaller scale investigations.

\section{Interstitial lung disease}

The use of quantitative CT to measure lung structure is not limited to regions of destroyed or hyperinflated lung, but it can also be used to measure the increase in lung tissue caused by fibrotic lung disease. CT-based investigation in the 1980s and 1990s focused on utilizing algorithms that examined the histogram distributions of the lung density. For example, Hartley et al. showed that frequency distribution of the apparent X-ray attenuation values was shifted towards denser lung in subjects with idiopathic pulmonary fibrosis and that this shift correlated with functional changes and the presence of macrophages and eosinophils in bronchoalveolar lavage fluid. ${ }^{31}$ Coxson et al. demonstrated that CT could be used to measure a decrease in air volume and a corresponding increase in tissue volume in idiopathic pulmonary fibrosis without actually changing the total lung mass. ${ }^{32}$ However, the drawback of these studies is that they do not provide a robust method to discriminate early disease from dense fibrosis or to provide a useful method to follow disease longitudinally. A major challenge for interstitial lung disease has been that, unlike emphysema, fibrotic lung disease lacks a standard HU threshold that can dichotomize the visualized lung tissue into normal and disease.

Another confounding issue with using CT to quantify tissue changes in fibrotic lung disease is that chronic tobacco smoke exposure has been linked to the development of both COPD and idiopathic pulmonary fibrosis. Furthermore, recent investigation suggests that the co-occurrence of the radiologic manifestations of these processes may be found in up to $10 \%$ of smokers. ${ }^{33}$ The pathway of disease progression in such individuals is unknown, and while it may diverge to a more restrictive or obstructive physiology, more detailed study of this overlap may provide insight into the factors associated with the development of end stage COPD and idiopathic pulmonary fibrosis. Therefore, it is increasingly clear that algorithms focused on tissue classification will have to integrate techniques that detect both emphysema and high attenuating interstitial lung disease.

For these reasons, recent investigation has focused on advanced texture based algorithms that have the potential to quantify the changes in lung densitometry and have the ability to discriminate visual patterns similar to assessment by a trained radiologist. ${ }^{34,35}$ However, there are multiple challenges facing such approaches including the computational expense of such algorithms, the need to isolate the parenchyma from the airways and vessels prior to performing an analysis (normal high attenuating 
structures can be misclassified as disease) and the presence of a large volume of high quality data that can be used to develop and validate such an algorithm. Despite these hurdles, several groups have made exciting progress in this area, and it is now realistic to anticipate robust software applications that may detect and quantify normal tissue as well as that exhibiting honeycombing, reticular and ground glass patterns of disease.

\section{Asthma}

Asthma is a disease of the airways and until recently has not been the focus of densitometric analysis. Attention has recently turned to using expiratory CT scans and a threshold technique to quantify the extent of 'gas trapping' that is present. It is thought that this could be a useful surrogate for small airway disease below the spatial resolution of the CT scanner. A recent study from the Severe Asthma Research Program showed that the extent of gas trapping measured using lung densitometry was associated with increased hospitalization, and those with the most severe gas trapping were also those most likely to need treatment in the intensive care unit. ${ }^{36}$

\section{CT OF AIRWAYS}

The other major focus of lung structure-function relationships is the airway. Because of their spatial resolution, CT scans seemed well positioned to become the method of choice to non-invasively measure airway wall dimensions (Fig. 3). Early studies focused on manual tracing of the airway wall, but since this technique was susceptible to variations caused by the display features of the CT images or inter and intra observer variability, attention quickly changed to automated airway analysis. In the intervening years, there have been numerous studies designed to develop and implement automated airway analysis algorithms. ${ }^{37-40}$ Many of these studies were used simple analysis such as the 'full-width at half maximum' algorithm, , ,11,38,41,42 but others have used more complex model-based approaches. ${ }^{37,39,40}$ While many convincing arguments have been made about the superiority of the model-based approaches, the full width at half maximum is still commonly used. However, a major drawback to all airway research is that there is still no consensus about the appropriate algorithm to use which limits comparison of results between centres.

The common parameters obtained from airway measurements are similar to those obtained using histology. These parameters include: total bronchial area, or outer airway wall area (Ao), the wall area (WA), the internal, or lumen, area (Ai), and the wall thickness (WT) (Fig. 4). All of these measurements were originally obtained by random or arbitrary selection of airways cut in cross-section on the transverse CT images. While this is a reasonable method for measuring airways, and has roots in histologic sampling of airways, investigators still needed to normalize the airway measurements so that comparisons between subjects could be performed. Initially, this was accomplished by calculating a value known as the wall area percent (WA\%: $100 *$ (wall area) / (lumen + wall area) ). However, there is an inherent 'reference trap' in the WA\% measurements where WA\% increases as total bronchial area decreases irrespective of changes in WA. Previous histology studies have shown that the square root of the airway WA was linearly related to the internal perimeter $(\mathrm{Pi})$ of the airway. Therefore, investigators have found that by plotting the Pi of all airways measured on CT against the square root of WA on a subject by subject basis, the resulting regression equation can be used to predict the square root of WA for an arbitrary airway with an internal perimeter of $10 \mathrm{~mm}$ (Pi10). This Pil0 value is proving to be a reliable standardized measurement of airway wall size that can be

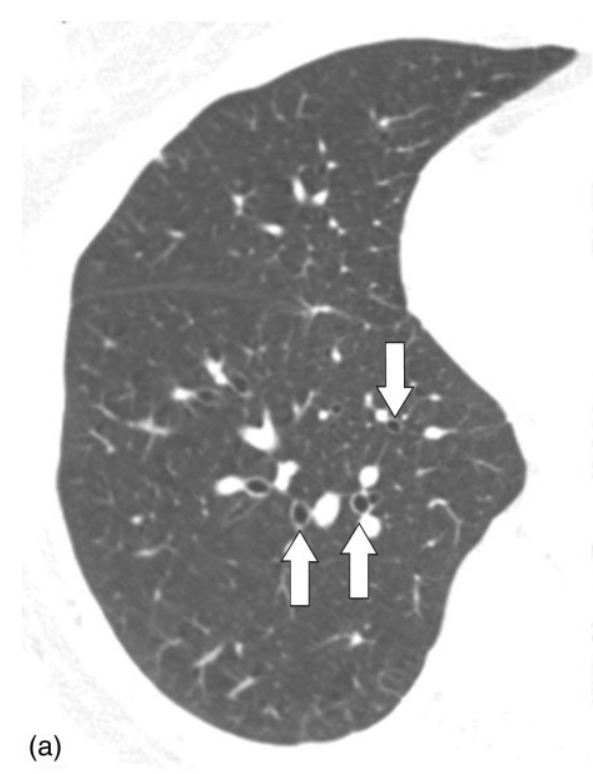

Respirology (2012) 17, 432-444

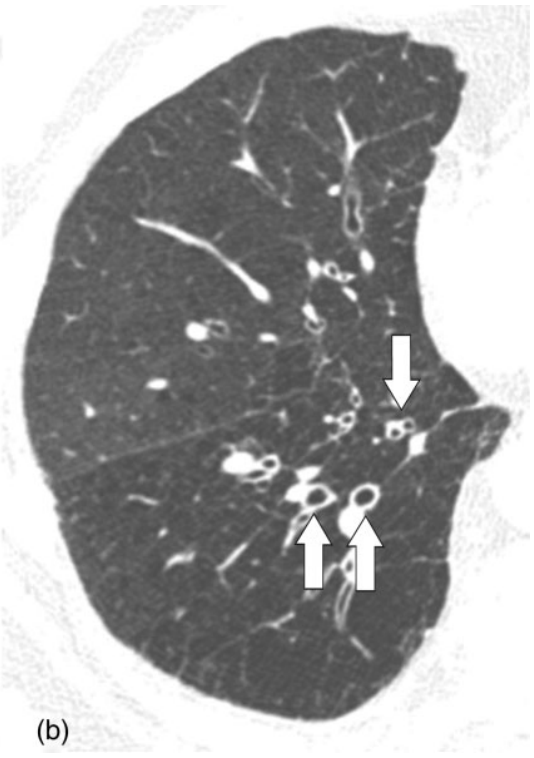

Figure 3 Computed tomographic images of airways. This figure shows two transverse computed tomography (CT) images of the left lung. The airways in image (a) seem to be thinner than the airways in image (b) suggesting that the CT scans can be used to quantify airway wall changes. 
Figure 4 Airway measurements. This figure shows a cartoon representation (image on the left) of the airway wall with the parameters measured from the airway indicated. These parameters are also noted in the expanded image of the computed tomography (CT) airway wall. The CT measurements are obtained using the full width at half maximum principle. $\mathrm{Pi}=$ \&thinsp internal perimeter of the airway wall. $A i=$ internal lumen area of the airway. $\mathrm{WA}=$ wall area. TBA $=$ total bron-
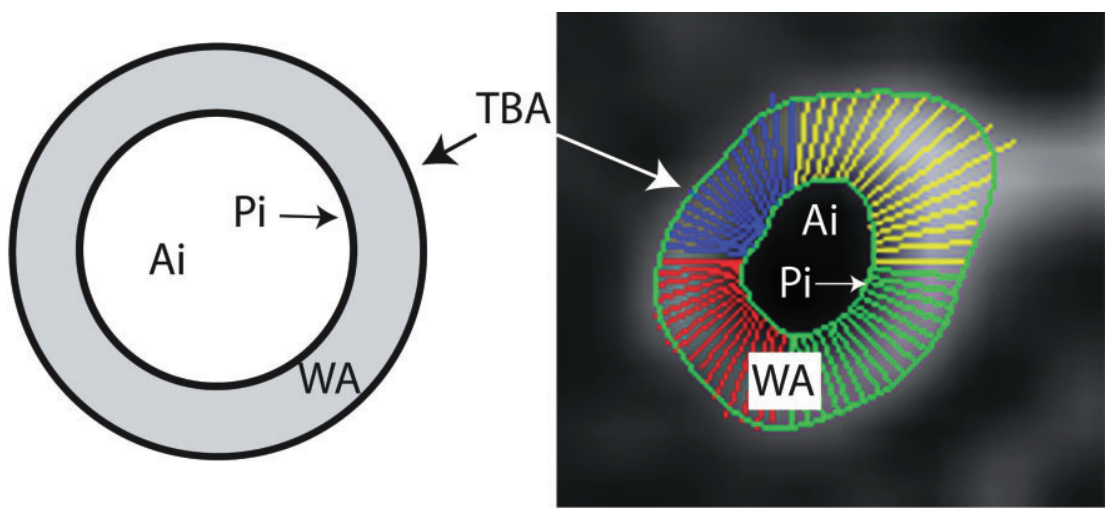
chial area (wall and lumen).

used to compare airway wall measurements between subjects.

In one of the first systematic analysis of airway morphology in smokers, Nakano et al. assessed the apical segment of the right upper lobe in 114 smokers. In their analysis, they observed that those subjects with the greatest WA\% (increased ratio of wall area to lumen area) had the lowest $\mathrm{FEV}_{1}$ expressed as a percent of predicted. ${ }^{11}$ Based upon this investigation, the WA\% has become the most commonly employed metric for clinical investigation largely because it has consistently provided the strongest correlation to spirometric measures of lung function. In a subsequent investigation, this same group demonstrated that central airway remodelling apparent on CT reflected distal histopathologic remodelling of the small airways, those with great central airway wall thickening had more small airway disease. ${ }^{43}$

Recently, with the advent and proliferation of multi-detector row CT scanners, airway analysis has switched to 'volumetric' analysis, whereby the entire bronchial tree is reconstructed and then the airway wall dimensions obtained at the midpoint between two branch points using multi-planar reformatted images. ${ }^{40,44}$ This was also thought to be advantageous, because it would allow only more peripheral airways to be measured, which may produce a stronger correlation with lung function. In fact, studies have shown that measurements of the fifth and sixth generation of the airway tree have better correlation with lung function than do more central airways. ${ }^{20,44}$ It is also thought that this approach will give better measurements of the airway dimensions, because it allows for a segment by segment comparison between individuals.

While these findings have compelled investigators to examine more and more distal airways, such measures are limited by the resolution of the CT images. Therefore, some investigators have turned their attention to densitometry measurements of expiratory CT scans. It is thought that if there is small airway remodelling, it causes 'gas trapping' on expiration, which can be quantified using a threshold analysis and a cut-off set very close to the theoretical X-ray attenuation value that represents maximal lung inflation, that is, total lung capacity divided by lung mass.
These studies, especially in asthma, have shown that these measurements of 'gas trapping' do correlate with clinical symptoms in severe asthmatics and in response to therapy ${ }^{36,45}$

Investigators have also begun to look beyond airway wall thickening to assess airway disease in smokers. Included in these efforts are quantitative assessments of mural density or attenuation. ${ }^{46}$ The premise behind these investigations is that as an airway wall thickens or remodels, both the shape and contents of the wall change. Normal bronchial cartilage may be gained or lost, and normal connective tissue is replaced by scar. Preliminary investigation suggests that airway wall attenuation may provide additional information regarding airway disease in smokers. ${ }^{46}$ Further work is needed to comprehensively understand the scanner to scanner variability and the influence of body habitus on these measures.

Recently, Hogg et al. introduced a new paradigm for airway disease in smokers. Not only does airway remodelling lead to obstruction of the small airways and expiratory airflow obstruction, but there appears to be an outright loss of airways in advanced COPD. ${ }^{47}$ Based upon these findings, Diaz et al. examined the chest CT scans of 50 smokers enrolled in the Lung Tissue Research Consortium and found that those subjects with more advanced emphysema have pruning of the central airways on CT scan (loss of airways in generations 5-8). ${ }^{48}$ Further, even after adjustment for densitometric measures of emphysema, the total airway count (sum of airway generations visible in the third to eighth generation starting from the apical segment of the right upper lobe) was an independent predictor of the BODE score, which is a validated multidimensional measure of mortality in COPD. Further histologic validation is needed to determine the extent to which airway loss manifests in the more proximal airway tree; however, airway drop out may be a marker of the extreme of airway disease.

\section{CT OF THE PULMONARY VASCULATURE}

Pulmonary vascular disease is an independent predictor of morbidity and mortality in COPD, and 
pathologic pulmonary vascular remodelling is found even in smokers with normal lung function. ${ }^{49-52}$ The mechanisms for this process likely include inflammation in milder COPD with hypoxic vasoconstriction and outright loss of parallel pathways due to emphysematous destruction of the tissue in more severe disease. While the standard visual assessment of pulmonary vascular remodelling includes measurements of the diameter of the main pulmonary artery, more recent investigations have demonstrated that remodelling of the distal intra-parenchymal pulmonary vasculature yields compelling insights into the relation of vascular disease and emphysema, its relation to pulmonary artery pressure and a potential link between pulmonary vascular remodelling and atherosclerotic disease as assessed by thoracic aortic calcification. ${ }^{53}$

In an attempt to assess pulmonary vascular remodelling at its earliest stages, Alford et al. undertook an investigation using central venous boluses of iodinated contrast agent. ${ }^{54}$ In a cohort of 43 subjects ( 17 normals, 12 smokers with no emphysema and normal lung function, 12 smokers with very mild emphysema), they demonstrated that changes in the pulmonary vasculature could be detected and quantitatively assessed at its very earliest stages. ${ }^{54}$ While such an approach is not amenable to population-based studies, these data may suggest that emphysema may begin as a vascular disease leading to a regional loss of tissue.

\section{EMERGING RESEARCH APPLICATIONS OF CT}

Advances in image processing and large-scale application of CT scanning in clinical investigation have led to compelling new insight into the clinical and physiologic impact of COPD. In the populationbased Multi Ethnic Study of Atherosclerosis, Barr et al. clearly demonstrated that emphysema and its associated hyperinflation compromises cardiac function through reductions in left ventricular filling, possibly due to occult pulmonary vascular remodelling. ${ }^{55}$ More recently, Han and colleagues depicted the very complex relationship between radiologic emphysema, airway disease and acute exacerbations of COPD. ${ }^{56}$ The results of this investigation may allow clinicians and researchers to identify who is at greatest risk for an acute exacerbations of COPD and maximize preventive therapies for such events and enrich clinical studies for subsequent investigation. Finally, CT imaging has become an essential part of minimally invasive lung volume reduction procedures such as the placement of one-way valves. These studies have shown that device placement can result in an overall decrease in lung volume ${ }^{20}$ and that incomplete interlobar fissures mitigate procedural benefit likely due to collateral ventilation. ${ }^{57}$

While these results are exciting, and it is through such investigation that new therapies and therapeutic approaches to care will be discovered, these advances don't come without concern. The clinical and research community is increasingly aware of the risks associated with the radiation exposure necessary for CT acquisition. The estimates of the associations between the dose of radiation and risk of cancer vary and may be as high as 1/80 lifetime risk from a single $\mathrm{CT}^{58}$ These risks will not preclude the use of CT imaging, but the clinical and research community must always weigh this concern with the potential benefit of having such data.

\section{MRI}

\section{Application to thoracic imaging}

Tissue contrast in conventional MRI stems from the perturbation of water- and fat-bound hydrogen atoms (otherwise known as protons $\left({ }^{1} \mathrm{H}\right)$ ) using a burst of radio-frequency energy. When the patient is in the 'magnet', they take with them the billions of protons that are randomly spinning in various directions in the body, but when placed in the scanner, protons line up parallel and anti-parallel to the strong magnetic field of the scanner. The MRI signal that we see derives from the tiny net fraction of protons ( 1 or $2 /$ million) that are aligned with the magnetic field of the scanner and after application of radio-frequency radiation, these undergo realignment that is detected and converted into the image.

Conventional ${ }^{1} \mathrm{H}$ MRI is readily available in most radiology departments, however until now, a number of fundamental challenges have limited its usefulness for lung imaging. Exquisite soft tissue threedimensional contrast of most organs in the body is achieved via the detection of water-bound protons in slightly different chemical environments. This contrast is dependent on the proton density of the tissues being examined, and unfortunately the lung has relatively low tissue density and therefore low proton density. This is one reason why thoracic MRI, even when optimized for the lung, results in images ${ }^{59,60}$ that resemble black holes, with the lung regions mainly devoid of contrast, tissue and morphological information. Compounding this, the lung architecture consists of millions of air-tissue interfaces on the micrometer scale. The juxtaposition of the different magnetic environments related to the tightly spaced air and tissue compartments result in so-called magnetic 'susceptibility artifacts' that accelerate signal decay. Taken together, low proton density and susceptibility artefacts mean that conventional pulmonary ${ }^{1} \mathrm{H}$ MRI must incorporate both short echo times and long acquisition times. For these reasons, the development of conventional thoracic MRI has been mainly overlooked as a clinical application, although its diagnostic potential was recognized by Mayo and Müller over two decades ago. ${ }^{61}$

Recently, there has been a renewed interest in the clinical potential of thoracic MRI stimulated by cardiac MRI developments, ${ }^{62}$ by novel pulmonary functional MRI using noble gas contrast agents ${ }^{63}$ as well as oxygen-enhanced ${ }^{64}$ and Fourierdecomposition proton MRI ${ }^{65,66}$ of the lung. While recent reviews of oxygen-enhanced proton $\mathrm{MRI}^{67,68}$ and noble gas MRI $^{63}$ have recently been published, 
here we focus on novel lung functional MRI using noble gases and their comparison to CT in acknowledgement of the unprecedented opportunity these methods provide for respiratory medicine.

\section{Structure-function MRI of the lung parenchyma}

The promise of pulmonary functional MRI was first recognized over 15 years ago with the landmark discovery of Albert and colleagues. ${ }^{69}$ Imaging typically takes place with the subject in breath-hold, 10-15 s after inhalation of a discrete volume of magnetized (or hyperpolarized) helium or xenon gas. As shown in Figure 5, for hyperpolarized lung functional MRI, imaging provides a way to estimate inhaled gas distribution in healthy young and older never smokers, and in subjects with asthma, COPD, cystic fibrosis and radiation-induced lung injury. These images provide a way to regionally describe and quantify those areas of the lung that appear to participate in gas distribution and those that do not. In healthy young adults, a single inhalation of hyperpolarized ${ }^{3} \mathrm{He}$ gas results in homogeneous signal (Fig. 5) suggesting that all areas of the lung are participating equally in gas distribution (for the purposes of this review, we will use the term ventilation and gas distribution interchangeably). In contrast, characteristic volumetric 'focal' ventilation defects are observed in COPD, asthma, cystic fibrosis, radiation-induced lung injury and surprisingly, even in otherwise healthy elderly never smokers $^{70,71}$ as regions that do not appear to contain gas signal. Focal ventilation defects are thought to correspond to areas of the lung that are not ventilated or perhaps poorly ventilated within the time course of a typical $10-15$ s breath-hold scan, ${ }^{72}$ but the exact eti-

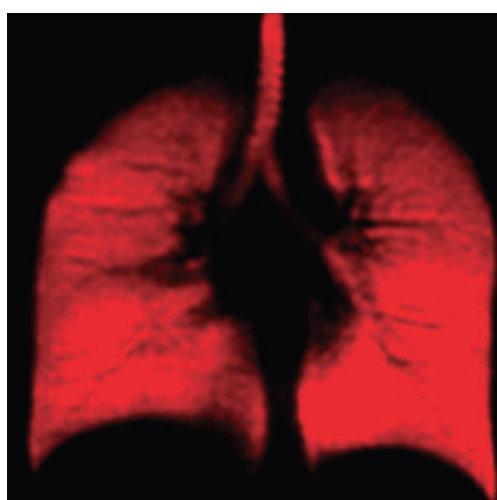

Healthy Young

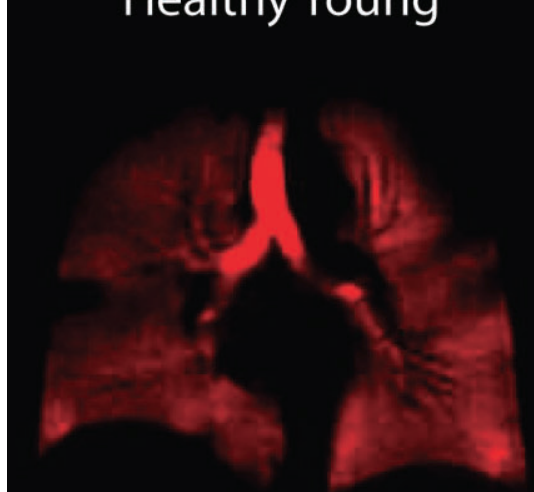

Healthy Elderly

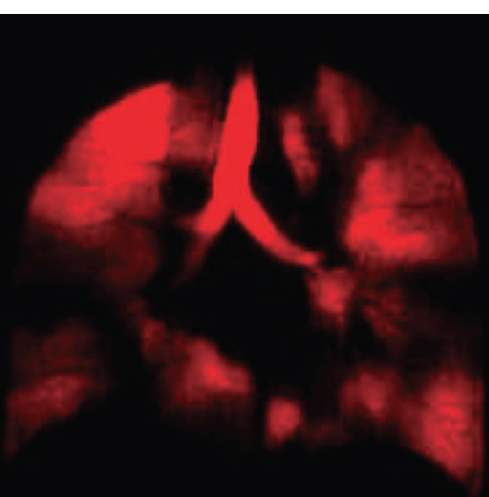

Asthma

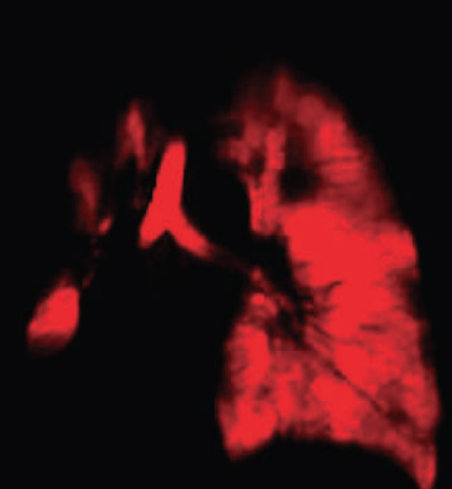

RILI
COPD

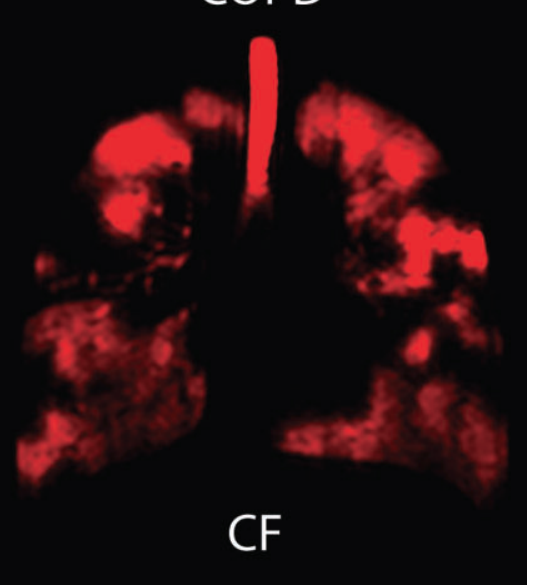

Figure 5 Hyperpolarized ${ }^{3} \mathrm{He}$ magnetic resonance imaging. Hyperpolarized ${ }^{3} \mathrm{He} \mathrm{MRI}$ coronal centre slice images for healthy young and old never smokers and subjects with asthma, chronic obstructive pulmonary disease (COPD), radiation-induced lung injury (RILI) and cystic fibrosis (CF). In young never-smokers, ${ }^{3} \mathrm{He}$ gas distribution (shown in red) is homogeneous, but in the elderly never smokers and subjects with respiratory disease, characteristic focal defects are clearly visible and can be measured qualitatively and quantitatively.

Healthy young never smoker: 26 -year-old female, $\mathrm{FEV}_{1}=95 \%, \mathrm{FEV}_{1} / \mathrm{FVC}=90 \%$

Asthma: 48-year-old female $\mathrm{FEV}_{1}=67 \%, \mathrm{FEV}_{1} / \mathrm{FVC}=65 \%$

COPD: 72-year-old male $\mathrm{FEV}_{1} 49 \%, \mathrm{FEV}_{1} / \mathrm{FVC}=54 \%$

Elderly never smoker: 73-year-old male $\mathrm{FEV}_{1}=104 \%, \mathrm{FEV}_{1} / \mathrm{FVC}=78 \%$

RILI: 55 -year-old male $\mathrm{FEV}_{1}=54 \%, \mathrm{FEV}_{1} / \mathrm{FVC}=73 \%$

CF: 21 -year-old male $\mathrm{FEV}_{1}=74 \%, \mathrm{FEV}_{1} / \mathrm{FVC}=71 \%$.

$\mathrm{FEV}_{1}$, forced expiratory volume in $1 \mathrm{~s}$; FVC, forced vital capacity. 

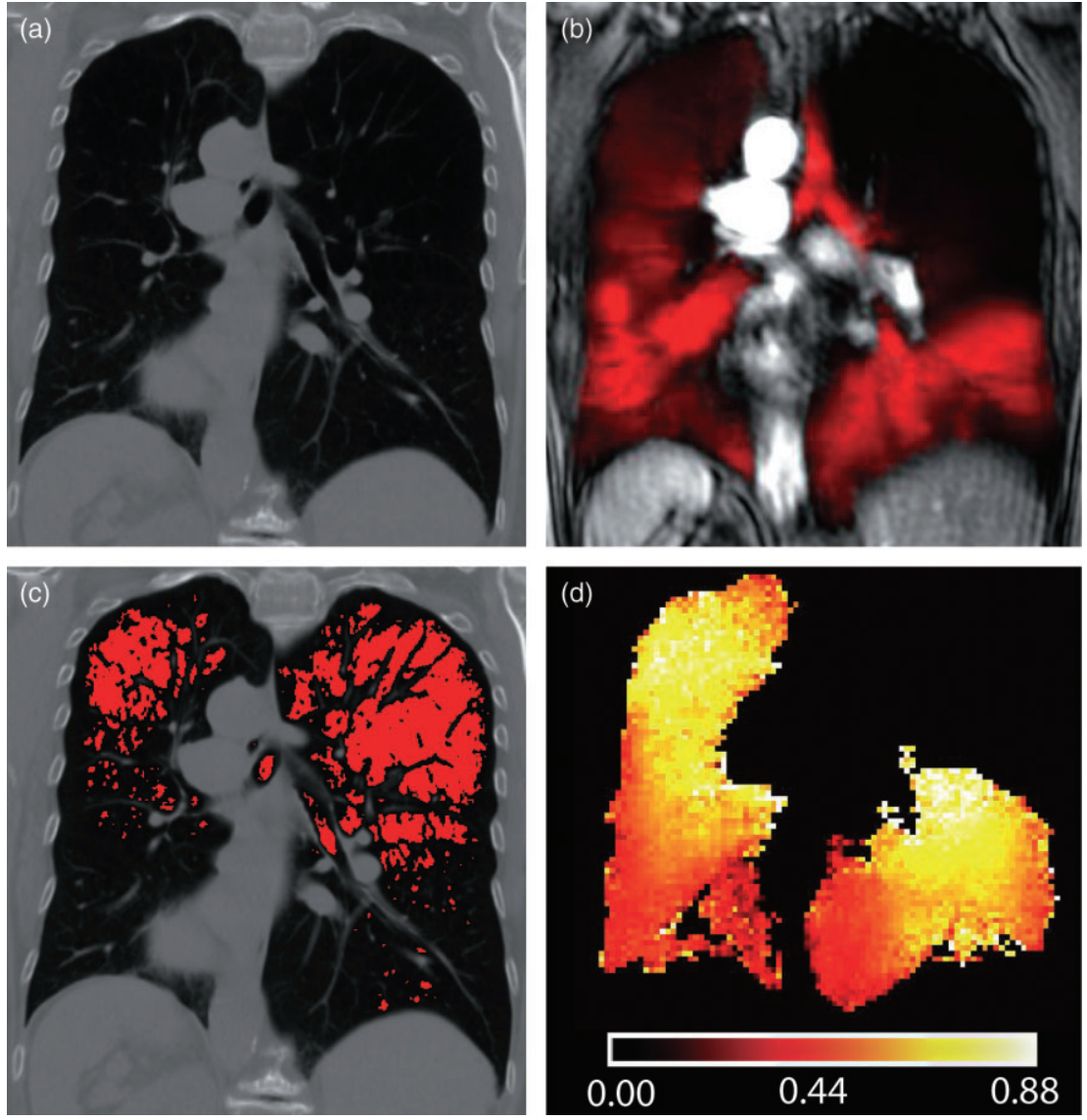

Figure 6 Computed tomography and ${ }^{3} \mathrm{He}$ magnetic resonance imaging (MRI) centre coronal slices for a 71-yr-old female with stage III chronic obstructive pulmonary disease (forced expiratory volume in $1 \mathrm{~s}\left(\mathrm{FEV}_{1}\right)=47 \%$ pred, $^{\mathrm{FEV}}$ / forced vital capacity $=41 \%$, diffusing capacity of carbon monoxide $=31 \%$ pred). (a) Centre slice coronal reconstruction MDCT (GE 64 slice) in greyscale. (b) Centre slice coronal ${ }^{1} \mathrm{H}$ MRI thoracic cavity in grey scale with co-registered hyperpolarized ${ }^{3} \mathrm{He}$ MRI static ventilation image in red. (c) Hounsfield unit threshold of $-950 \mathrm{HU}$ in red shown over MDCT centre coronal slice. (d) Hyperpolarized ${ }^{3} \mathrm{He}$ MRI apparent diffusion coefficient map generated from diffusion-weighted imaging $(b=$ $1.6 \mathrm{~s} / \mathrm{cm}^{2}$ ). ology of these functional abnormalities in relation to airway and parenchyma structural abnormalities has not yet been determined.

Based on our current understanding of the strong relationship between lung structure and function, it is generally assumed that when lung tissue and morphology appear normal on X-ray-based images, lung function is also likely normal and vice versa. Hyperpolarized ${ }^{3} \mathrm{He}$ MRI has the advantage in that it provides simultaneous structure-function information, and this unique ability has been used to test these assumptions. For example, as previously described ${ }^{71}$ and shown in another COPD patient in Figure 6, when ${ }^{3} \mathrm{He}$ MRI functional ventilation images of a patient with GOLD stage 3 COPD are directly compared with $\mathrm{CT}$ images, there is no anatomical or tissue heterogeneity detected in the CT images that would be predictive of the apparent functional abnormalities (especially note the lack of function in the left upper lobes) revealed by ${ }^{3} \mathrm{He}$ MRI. This suggests that MRI provides important functional information not provided by $\mathrm{CT}$ and furthermore challenges our assumptions of lung function based on CT lung structural findings. Focal ${ }^{3} \mathrm{He}$ gas distribution abnormalities can be directly quantified as the ${ }^{3} \mathrm{He}$ MRI ventilation defect volume, ${ }^{71}$ or as the normalized ventilation defect percent ${ }^{73,74}$ and percent ventilation volume, ${ }^{75}$ all of which have excellent reproducibility. ${ }^{73}$ It is important to note that all these functional measurements of the parenchyma depend on gas flow through the airways, thereby enabling an indirect measurement of airway patency and function. ${ }^{76}$

Another important property of noble gas MRI that provides a unique non-invasive way to measure lung microstructure is their small size (relative to inhaled aerosolized or nebulized drug therapy) and corresponding high self-diffusion rates. MR methods can be used that are sensitive to gas self-diffusion, and these provide a measure of gas displacement in the lung that is dependent on random Brownian motion (as opposed to transmembrane gas diffusion). The apparent diffusion coefficient of inhaled gas can be derived, reflecting the apparent decreased displacement of the gas when inhaled and restricted by the airways and airspaces. For example, for diffusion times on the order of milliseconds, the average displacement of helium atoms by virtue of its selfdiffusion is the same order of magnitude as alveolar diameters (a few hundred micrometers), and therefore these measurements are sensitive to differences in alveolar sizes. As shown in Figures 6 and 7, ${ }^{3} \mathrm{He}$ and ${ }^{129} \mathrm{Xe}$ apparent diffusion coefficient provide a surrogate measurement of airspace size and accordingly of emphysematous damage ${ }^{77-79}$ and gas trapping, ${ }^{80}$ strongly correlating with diffusing capacity of carbon monoxide ${ }^{81}$ and histological measurements of lung surface area. ${ }^{82,83}$ As shown in Figure 7, the ${ }^{3} \mathrm{He}$ or ${ }^{129} \mathrm{Xe}$ apparent diffusion coefficient image can be interrogated on a pixel-by-pixel basis to provide a quantitative apparent diffusion coefficient map depicts 

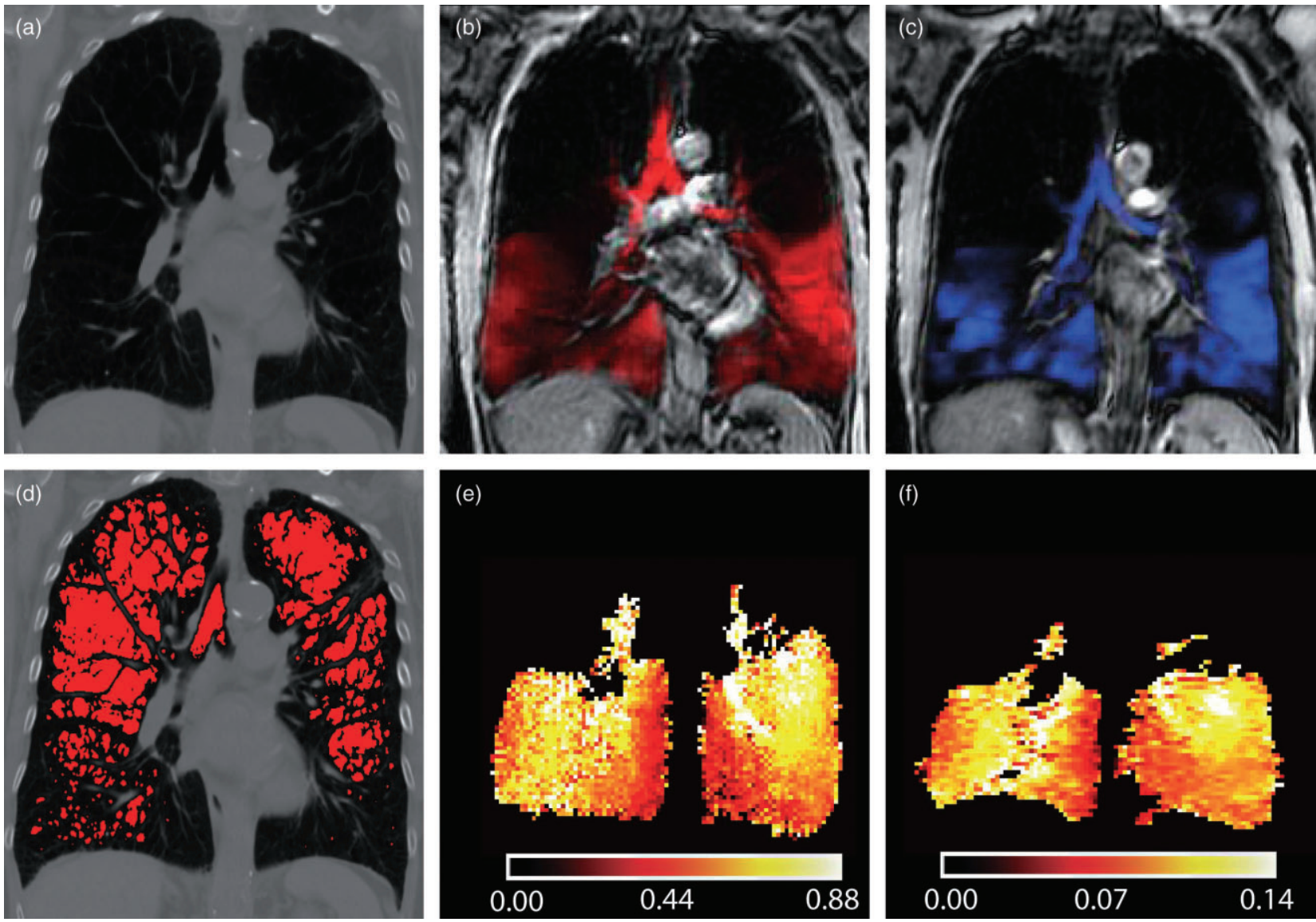

Figure 7 Hyperpolarized ${ }^{3} \mathrm{He}$ and ${ }^{129} \mathrm{Xe}$ magnetic resonance imaging (MRI) and $\mathrm{CT}$ in a female subject with stage II chronic obstructive pulmonary disease (forced expiratory volume in $1 \mathrm{~s}\left(\mathrm{FEV}_{1}\right)=52 \%$ pred, $\mathrm{FEV}_{1} / \mathrm{forced}$ vital vapacity $=42 \%$, diffusing capacity of carbon monoxide $=18 \%$ pred). (a) Centre slice coronal reconstruction MDCT (GE 64 slice) in grey scale. (b) Centre slice coronal ${ }^{1} \mathrm{H}$ MRI thoracic cavity in grey scale with co-registered hyperpolarized ${ }^{3} \mathrm{He} \mathrm{MRI}$ static ventilation in red. (c) Centre slice coronal ${ }^{1} \mathrm{H}$ MRI thoracic cavity in grey scale with co-registered hyperpolarized ${ }^{129} \mathrm{Xe}$ MRI static ventilation in blue. (d) Hounsfield unit threshold of -950HU in red shown over MDCT centre coronal slice. (e) Hyperpolarized ${ }^{3} \mathrm{He} \mathrm{MRI}$ apparent diffusion coefficient map generated from diffusion-weighted imaging $\left(b=1.6 \mathrm{~s} / \mathrm{cm}^{2}\right)$. (f) Hyperpolarized ${ }^{129} \mathrm{Xe} \mathrm{MRI}$ apparent diffusion coefficient map generated from diffusion-weighted imaging $\left(b=30 \mathrm{~s} / \mathrm{cm}^{2}\right)$.

emphysematous destruction in those regions of the lung participating in ventilation. ${ }^{129}$ Xenon MRI has the added advantage of being freely diffusible across the alveolar capillary membrane, and simultaneous imaging of the gas in the alveolus, in the alveolar wall and blood is now possible ${ }^{84}$ opening up new opportunities for understanding ventilation-perfusion abnormalities in respiratory disease. Importantly, as shown in Figure 7, the functional images provided by ${ }^{3} \mathrm{He}$ and ${ }^{129} \mathrm{Xe}$ are qualitatively and quantitatively indistinguishable, which given the limited availability and high cost of ${ }^{3} \mathrm{He}$ gas ${ }^{63}$ bodes well for the clinical and research translation of ${ }^{129} \mathrm{Xe}$ MRI in future. It is also possible to exploit the accelerated gas signal decay in the presence of oxygen in the lung by measuring the differential rates of decay of ${ }^{3} \mathrm{He}$ or ${ }^{129} \mathrm{Xe}^{85,86}$ related to heterogeneity in oxygen partial pressures, providing an in vivo window on the most fundamental aspect of lung function. Finally, the use of noble gas MRI in longitudinal and treatment studies provides new windows on our understanding of smokingrelated disease. Recent work has shown the sensitive and accelerated detection of COPD progression in ex-smokers over a 2-year period as compared to standard spirometry and plethysmography measurements that showed no change. ${ }^{87}$ In addition, dramatic improvements in gas distribution postbronchodilator were shown ${ }^{88}$ in COPD ex-smokers even in subjects with modest or no apparent $\mathrm{FEV}_{1}$ measured response, further evidence of the power of this method when applied in treatment studies.

\section{Structure-function MRI of airways}

One technological advantage of thoracic MRI is that it may be used to dynamically interrogate gas flow and delivery via the airways. ${ }^{89-92}$ Such measurements may reflect regions with either airway or parenchymal abnormalities, or potentially an admixture of the two. 
Importantly, dynamic measurements are not dependent on the proximal airway structure for measurements of distal airway remodelling but provide more direct measurements of the distal small airways. Dynamic imaging can be performed as a wash-in or wash-out procedure, showing the filling and emptying of the lung in respiratory disease. The clinical potential of this approach is yet to be exploited, but certainly the measurements provided can be used to test hypotheses related to underlying disease mechanisms in asthma, COPD and cystic fibrosis.

\section{SUMMARY AND CONCLUSIONS}

CT and MRI are maturing technologies that have provided new insight into the remodelling of the airways, parenchyma and the pulmonary vasculature. The strength of CT lies in its speed, availability and its technical ability to provide highly detailed measures of lung structure, while MRI provides insight into lung function on the macro and microscopic level. While good agreement between MRI and CT pulmonary findings has been previously reported, it is clear that lung imaging using MRI currently cannot surpass high-resolution CT in terms of speed, image contrast and content as well as spatial resolution. In fact, because of the inherent limitations based on the physics of MRI itself, pulmonary MRI may never replace high-resolution CT for lung disease diagnosis and monitoring. However, in recognition of the fact that the lung is the most radiosensitive organ in the chest, ${ }^{93,94}$ and longitudinal monitoring will increase the risk of cumulative radiation doses, ${ }^{95}$ especially in children, MRI, even conventional ${ }^{1} \mathrm{H}$ MRI, should be considered. The information derived is certainly complementary to CT and in some longitudinal applications in chronic disease is superior to CT because of its relatively low-risk and high-lung function information content. These and other techniques will continue to improve understanding of disease pathophysiology and may ultimately improve the care of patients with COPD.

\section{ACKNOWLEDGEMENTS}

GRW was supported by grants K23 HL089353, R01 HL107246, U10 Hl074428 and N01-HC-25195. GP gratefully acknowledges support from a Canadian Institutes of Health Research (CIHR) New Investigator Award and research funding from CIHR Operating grants MOP\# 97748, MOP\# 106437, CIHR Team Grant FRN\# 97687 and a National Science and Engineering Research Council (NSERC) Discovery Grant. HOC was supported by a Roberta R. Miller Fellowship in Thoracic Imaging from the British Columbia Lung Association and was also supported, in part, by the University of Pittsburgh COPD SCCOR NIH 1P50 HL084948 and R01 HL085096 from the National Heart, Lung and Blood Institute, National Institutes of Health, Bethesda, MD to the University of Pittsburgh. Dr Coxson also acknowledges the Canadian
Institutes of Health Research Clinical Initiative Grant FRN-97687.

\section{REFERENCES}

1 Hayhurst MD, Flenley DC, McLean A et al. Diagnosis of pulmonary emphysema by computerized tomography. Lancet 1984; 2: 320-22.

2 Gould GA, MacNee W, McLean A et al. CT measurements of lung density in life can quantitate distal airspace enlargement-an essential defining feature of human emphysema. Am. Rev. Respir. Dis. 1988; 137: 380-92.

3 Müller NL, Staples CA, Miller RR et al. 'Density mask'. An objective method to quantitate emphysema using computed tomography. Chest 1988; 94: 782-7.

4 Gevenois PA, De Vuyst P, de Maertelaer V et al. Comparison of computed density and microscopic morphometry in pulmonary emphysema. Am. J. Respir. Crit. Care Med. 1996; 154: 187-92.

5 Madani A, Zanen J, de Maertelaer V et al. Pulmonary emphysema: objective quantification at multi-detector row CT-comparison with macroscopic and microscopic morphometry. Radiology 2006; 238: 1036-43.

6 Dirksen A, Dijkman JH, Madsen IF et al. A randomized clinical trial of a-1 antitrypsin augmentation therapy. Am. J. Respir. Crit. Care Med. 1999; 160: 1468-72.

7 Dirksen A, Piitulainen E, Parr DG et al. Exploring the role of CT densitometry: a randomised study of augmentation therapy in alphal-antitrypsin deficiency. Eur. Respir. J. 2009; 33: 1345-53.

8 Grydeland TB, Dirksen A, Coxson HO et al. Quantitative computed tomography measures of emphysema and airway wall thickness are related to respiratory symptoms. Am. J. Respir. Crit. Care Med. 2010; 181: 353-9.

9 Grydeland TB, Thorsen E, Dirksen A et al. Quantitative CT measures of emphysema and airway wall thickness are related to D(L)CO. Respir. Med. 2011; 105: 343-51.

10 Mets OM, Buckens CF, Zanen P et al. Identification of chronic obstructive pulmonary disease in lung cancer screening computed tomographic scans. JAMA 2011; 306: 1775-81.

11 Nakano Y, Muro S, Sakai H et al. Computed tomographic measurements of airway dimensions and emphysema in smokers. Correlation with lung function. Am. J. Respir. Crit. Care Med. 2000; 162: 1102-8.

12 Nakano Y, Sakai H, Muro S et al. Comparison of low attenuation areas on computed tomographic scans between inner and outer segments of the lung in patients with chronic obstructive pulmonary disease: incidence and contribution to lung function. Thorax 1999; 54: 384-9.

13 Parr DG, Stoel BC, Stolk J et al. Pattern of emphysema distribution in alphal-antitrypsin deficiency influences lung function impairment. Am. J. Respir. Crit. Care Med. 2004; 170: 1172-8.

14 Shaker SB, Dirksen A, Ulrik CS et al. The effect of inhaled corticosteroids on the development of emphysema in smokers assessed by annual computed tomography. COPD 2009; 6: 10411.

15 Ashraf H, Lo P, Shaker SB et al. Short-term effect of changes in smoking behaviour on emphysema quantification by CT. Thorax 2011; 66: 55-60.

16 Yuan R, Hogg JC, Pare PD et al. Prediction of the rate of decline in FEV(1) in smokers using quantitative computed tomography. Thorax 2009; 64: 944-9.

17 Boedeker KL, McNitt-Gray MF, Rogers SR et al. Emphysema: effect of reconstruction algorithm on CT imaging measures. Radiology 2004; 232: 295-301.

18 Stoel BC, Bode F, Rames A et al. Quality control in longitudinal studies with computed tomographic densitometry of the lungs. Proc. Am. Thorac. Soc. 2008; 5: 929-33.

19 Yuan R, Mayo JR, Hogg JC et al. The effects of radiation dose and CT manufacturer on measurements of lung densitometry. Chest 2007; 132: 617-23. 
20 Coxson HO. Quantitative chest tomography in COPD research: chairman's summary. Proc. Am. Thorac. Soc. 2008; 5: 874-7.

21 Mishima M, Hirai T, Itoh $\mathrm{H}$ et al. Complexity of terminal airspace geometry assessed by lung computed tomography in normal subjects and patients with chronic obstructive pulmonary disease. Proc. Natl Acad. Sci. U.S.A. 1999; 96: 8829-34.

22 Coxson HO, Whittall KP, Nakano Y et al. Selection of patients for lung volume reduction surgery using a power law analysis of the computed tomographic scan. Thorax 2003; 58: 510-14.

23 Martinez FJ, Curtis JL, Sciurba F et al. Sex differences in severe pulmonary emphysema. Am. J. Respir. Crit. Care Med. 2007; 176: 243-52.

24 Madani A, Van Muylem A, de Maertelaer V et al. Pulmonary emphysema: size distribution of emphysematous spaces on multidetector CT images-comparison with macroscopic and microscopic morphometry. Radiology 2008; 248: 1036-41.

25 Gietema HA, Müller NL, Fauerbach PV et al. Quantifying the extent of emphysema: factors associated with radiologists' estimations and quantitative indices of emphysema severity using the ECLIPSE cohort. Acad. Radiol. 2011; 18: 661-71.

26 Uppaluri R, Mitsa T, Sonka M et al. Quantification of pulmonary emphysema from lung computed tomography images. Am. J. Respir. Crit. Care Med. 1997; 156: 248-54.

27 Chabat F, Yang GZ, Hansell DM. Obstructive lung diseases: texture classification for differentiation at CT. Radiology 2003; 228: 871-7.

28 Sluimer IC, van Waes PF, Viergever MA et al. Computer-aided diagnosis in high resolution CT of the lungs. Med. Phys. 2003; 30: 3081-90.

29 Sorensen L, Shaker SB, de Bruijne M. Quantitative analysis of pulmonary emphysema using local binary patterns. IEEE Trans. Med. Imaging 2010; 29: 559-69.

30 Xu Y, Sonka M, McLennan G et al. MDCT-based 3-D texture classification of emphysema and early smoking related lung pathologies. IEEE Trans. Med. Imaging 2006; 25: 464-75.

31 Hartley PG, Galvin JR, Hunninghake GW et al. High-resolution CT-derived measures of lung density are valid indexes of interstitial lung disease. J. Appl. Physiol. 1994; 76: 271-7.

32 Coxson HO, Hogg JC, Mayo JR et al. Quantification of idiopathic pulmonary fibrosis using computed tomography and histology. Am. J. Respir. Crit. Care Med. 1997; 155: 1649-56.

33 Washko GR, Hunninghake GM, Fernandez IE et al. Lung volumes and emphysema in smokers with interstitial lung abnormalities. N. Engl. J. Med. 2011; 364: 897-906.

34 Kim HG, Tashkin DP, Clements PJ et al. A computer-aided diagnosis system for quantitative scoring of extent of lung fibrosis in scleroderma patients. Clin. Exp. Rheumatol. 2010; 28: S2635.

35 Zavaletta VA, Bartholmai BJ, Robb RA. High resolution multidetector CT-aided tissue analysis and quantification of lung fibrosis. Acad. Radiol. 2007; 14: 772-87.

36 Busacker A, Newell JD, Jr, Keefe T et al. A multivariate analysis of risk factors for the air-trapping asthmatic phenotype as measured by quantitative CT analysis. Chest 2009; 135: 48-56.

37 King GG, Müller NL, Whittall KP et al. An analysis algorithm for measuring airway lumen and wall areas from high-resolution computed tomographic data. Am. J. Respir. Crit. Care Med. 2000; 161: $574-80$.

38 Nakano Y, Whittall KP, Kalloger SE et al. Development and validation of human airway analysis algorithm using multidetector row CT. Proc. SPIE 2002; 4683: 460-69.

39 Reinhardt JM, D’Souza ND, Hoffman EA. Accurate measurement of intrathoracic airways. IEEE Trans. Med. Imaging 1997; 16: 82027.

40 Tschirren J, Hoffman EA, McLennan G et al. Intrathoracic airway trees: segmentation and airway morphology analysis from lowdose CT scans. IEEE Trans. Med. Imaging 2005; 24: 1529-39.

41 Niimi A, Matsumoto H, Amitani R et al. Airway wall thickness in asthma assessed by computed tomography. Relation to clinical indices. Am. J. Respir. Crit. Care Med. 2000; 162: 1518-23.
42 Nishimura M. Application of three-dimensional airway algorithms in a clinical study. Proc. Am. Thorac. Soc. 2008; 5: 910-14.

43 Nakano Y, Wong JC, de Jong PA et al. The prediction of small airway dimensions using computed tomography. Am. J. Respir. Crit. Care Med. 2005; 171: 142-6.

44 Hasegawa M, Nasuhara Y, Onodera Y et al. Airflow limitation and airway dimensions in chronic obstructive pulmonary disease. Am. J. Respir. Crit. Care Med. 2006; 173: 1309-15.

45 Zeidler MR, Kleerup EC, Goldin JG et al. Montelukast improves regional air-trapping due to small airways obstruction in asthma. Eur. Respir. J. 2006; 27: 307-15.

46 Washko GR, Dransfield MT, Estepar RS et al. Airway wall attenuation: a biomarker of airway disease in subjects with COPD. J. Appl. Physiol. 2009; 107: 185-91.

47 McDonough JE, Yuan R, Suzuki M et al. Small-airway obstruction and emphysema in chronic obstructive pulmonary disease. N. Engl. J. Med. 2011; 365: 1567-75.

48 Diaz AA, Valim C, Yamashiro T et al. Airway count and emphysema assessed by chest CT imaging predicts clinical outcome in smokers. Chest 2010; 138: 880-87.

49 Chatila WM, Thomashow BM, Minai OA et al. Comorbidities in chronic obstructive pulmonary disease. Proc. Am. Thorac. Soc. 2008; 5: 549-55.

50 Chaouat A, Naeije R, Weitzenblum E. Pulmonary hypertension in COPD. Eur. Respir. J. 2008; 32: 1371-85.

51 Barbera JA, Riverola A, Roca J et al. Pulmonary vascular abnormalities and ventilation-perfusion relationships in mild chronic obstructive pulmonary disease. Am. J. Respir. Crit. Care Med. 1994; 149: 423-9.

52 Hale KA, Niewoehner DE, Cosio MG. Morphologic changes in the muscular pulmonary arteries: relationship to cigarette smoking, airway disease, and emphysema. Am. Rev. Respir. Dis. 1980; 122: 273-8.

53 Matsuoka S, Yamashiro T, Diaz A et al. The relationship between small pulmonary vascular alteration and aortic atherosclerosis in chronic obstructive pulmonary disease: quantitative CT analysis. Acad. Radiol. 2011; 18: 40-46.

54 Alford SK, van Beek EJ, McLennan G et al. Heterogeneity of pulmonary perfusion as a mechanistic image-based phenotype in emphysema susceptible smokers. Proc. Natl Acad. Sci. U.S.A. 2010; 107: 7485-90.

55 Barr RG, Bluemke DA, Ahmed FS et al. Percent emphysema, airflow obstruction, and impaired left ventricular filling. N. Engl. J. Med. 2010; 362: 217-27.

56 Han MK, Kazerooni EA, Lynch DA et al. Chronic obstructive pulmonary disease exacerbations in the COPDGene study: associated radiologic phenotypes. Radiology 2011; 261: 176-83.

57 Sciurba FC, Ernst A, Herth FJ et al. A randomized study of endobronchial valves for advanced emphysema. N. Engl. J. Med. 2010; 363: $1233-44$.

58 Smith-Bindman R, Lipson J, Marcus R et al. Radiation dose associated with common computed tomography examinations and the associated lifetime attributable risk of cancer. Arch. Intern. Med. 2009; 169: 2078-86.

59 Kauczor HU, Ley S. Thoracic magnetic resonance imaging 1985 to 2010. J. Thorac. Imaging 2010; 25: 34-8.

60 Kirby MA, Owrangi J, Wong S et al. Pulmonary magnetic resonance imaging of the obstructive airways disease. Minerva Pneumol. 2011; 50: 17-19.

61 Mayo JR, MacKay A, Müller NL. MR imaging of the lungs: value of short TE spin-echo pulse sequences. AJR Am. J. Roentgenol. 1992; 159: 951-6.

62 Finn JP, Nael K, Deshpande V et al. Cardiac MR imaging: state of the technology. Radiology 2006; 241: 338-54.

63 Fain S, Schiebler ML, McCormack DG et al. Imaging of lung function using hyperpolarized helium-3 magnetic resonance imaging: review of current and emerging translational methods and applications. J. Magn. Reson. Imaging 2010; 32: 1398-408.

64 Matsuoka S, Hunsaker AR, Gill RR et al. Functional MR imaging of the lung. Magn. Reson. Imaging Clin. N. Am. 2008; 16: 275-89. 
65 Bauman G, Lutzen U, Ullrich M et al. Pulmonary functional imaging: qualitative comparison of Fourier decomposition MR imaging with SPECT/CT in porcine lung. Radiology 2011; 260: 551-9.

66 Bauman G, Pauderbach M, Deimling M et al. Non-contrastenhanced perfusion and ventilation assessment of the human lung by means of Fourier decomposition in proton MRI. Magn. Reson. Med. 2009; 62: 656-44.

67 Ohno Y, Hatabu H. Basics concepts and clinical applications of oxygen-enhanced MR imaging. Eur. J. Radiol. 2007; 64: 320-28.

68 Ohno Y, Koyama H, Yoshikawa T et al. Pulmonary magnetic resonance imaging for airway diseases. J. Thorac. Imaging 2011; 26: 301-16.

69 Albert MS, Cates GD, Driehuys B et al. Biological magnetic resonance imaging using laser-polarized 129Xe. Nature 1994; 370: 199-201.

70 Parraga G, Mathew L, Etemad-Rezai R et al. Hyperpolarized 3He magnetic resonance imaging of ventilation defects in healthy elderly volunteers: initial findings at 3.0 Tesla. Acad. Radiol. 2008; 15: $776-85$.

71 Parraga G, Ouriadov A, Evans A et al. Hyperpolarized 3 He ventilation defects and apparent diffusion coefficients in chronic obstructive pulmonary disease: preliminary results at 3.0 Tesla. Invest. Radiol. 2007; 42: 384-91.

72 Mathew L, Kirby M, Etemad-Rezai R et al. Hyperpolarized (3)He magnetic resonance imaging: preliminary evaluation of phenotyping potential in chronic obstructive pulmonary disease. Eur. J. Radiol. 2011; 79: 140-46.

73 Mathew L, Evans A, Ouriadov A et al. Hyperpolarized 3He magnetic resonance imaging of chronic obstructive pulmonary disease: reproducibility at 3.0 tesla. Acad. Radiol. 2008; 15: 1298311.

74 Mathew L, Gaede S, Wheatley A et al. Detection of longitudinal lung structural and functional changes after diagnosis of radiation-induced lung injury using hyperpolarized $3 \mathrm{He}$ magnetic resonance imaging. Med. Phys. 2010; 37: 22-31.

75 Woodhouse N, Wild JM, Paley MN et al. Combined helium-3/ proton magnetic resonance imaging measurement of ventilated lung volumes in smokers compared to never-smokers. J. Magn. Reson. Imaging 2005; 21 : 365-9.

76 Leary D, Bhatawadekar SA, Parraga G et al. Modeling stochastic and spatial heterogeneity in a human airway tree to determine variation in respiratory system resistance. J. Appl. Physiol. 2011; Oct 13. [Epub ahead of print] PMID: 21998266.

77 de Lange EE, Mugler JP 3rd, Brookeman JR et al. Lung air spaces: MR imaging evaluation with hyperpolarized 3He gas. Radiology 1999; 210: 851-7.

78 Kauczor HU, Ebert M, Kreitner KF et al. Imaging of the lungs using 3He MRI: preliminary clinical experience in 18 patients with and without lung disease. J. Magn. Reson. Imaging 1997; 7: 538-43.

79 Kauczor HU, Hofmann D, Kreitner KF et al. Normal and abnormal pulmonary ventilation: visualization at hyperpolarized He-3 MR imaging. Radiology 1996; 201: 564-8.

80 Evans A, McCormack D, Ouriadov A et al. Anatomical distribution of $3 \mathrm{He}$ apparent diffusion coefficients in severe chronic obstructive pulmonary disease. J. Magn. Reson. Imaging 2007; 26: $1537-47$

81 Ley S, Zaporozhan J, Morbach A et al. Functional evaluation of emphysema using diffusion-weighted 3Helium-magnetic resonance imaging, high-resolution computed tomography, and lung function tests. Invest. Radiol. 2004; 39: 427-34.

82 Tanoli TS, Woods JC, Conradi MS et al. In vivo lung morphometry with hyperpolarized $3 \mathrm{He}$ diffusion MRI in canines with induced emphysema: disease progression and comparison with computed tomography. J. Appl. Physiol. 2007; 102: 477-84.

83 Woods JC, Choong CK, Yablonskiy DA et al. Hyperpolarized 3He diffusion MRI and histology in pulmonary emphysema. Magn. Reson. Med. 2006; 56: 1293-300.

84 Mugler JP 3rd, Altes TA, Ruset IC et al. Simultaneous magnetic resonance imaging of ventilation distribution and gas uptake in the human lung using hyperpolarized xenon-129. Proc. Natl Acad. Sci. U.S.A. 2010; 107: 21707-12.

85 Fischer MC, Kadlecek S, Yu J et al. Measurements of regional alveolar oxygen pressure using hyperpolarized 3He MRI. Acad. Radiol. 2005; 12: 1430-39.

$86 \mathrm{Yu}$ J, Rajaei S, Ishii M et al. Measurement of pulmonary partial pressure of oxygen and oxygen depletion rate with hyperpolarized helium-3 MRI: a preliminary reproducibility study on pig model. Acad. Radiol. 2008; 15: 702-12.

87 Kirby M, Mathew L, Wheatley A et al. Chronic obstructive pulmonary disease: longitudinal hyperpolarized (3)He MR imaging. Radiology 2010; 256: 280-89.

88 Kirby M, Mathew L, Heydarian M et al. Chronic obstructive pulmonary disease: quantification of bronchodilator effects by using hyperpolarized He MR imaging. Radiology 2011; 261: 28392

89 Holmes JH, Korosec FR, Du J et al. Imaging of lung ventilation and respiratory dynamics in a single ventilation cycle using hyperpolarized He-3 MRI. J. Magn. Reson. Imaging 2007; 26: 63036.

90 Koumellis P, van Beek EJ, Woodhouse N et al. Quantitative analysis of regional airways obstruction using dynamic hyperpolarized 3He MRI-preliminary results in children with cystic fibrosis. J. Magn. Reson. Imaging 2005; 22: 420-26.

91 Tooker AC, Hong KS, McKinstry EL et al. Distal airways in humans: dynamic hyperpolarized 3He MR imaging-feasibility. Radiology 2003; 227: 575-9.

92 Tzeng YS, Hoffman E, Cook-Granroth J et al. Investigation of hyperpolarized $3 \mathrm{He}$ magnetic resonance imaging utility in examining human airway diameter behavior in asthma through comparison with high-resolution computed tomography. Acad. Radiol. 2008; 15: 799-808.

93 Angel E, Yaghmai N, Jude CM et al. Dose to radiosensitive organs during routine chest CT: effects of tube current modulation. AJR Am. J. Roentgenol. 2009; 193: 1340-45.

94 Mayo JR, Aldrich J, Müller NL. Radiation exposure at chest CT: a statement of the Fleischner Society. Radiology 2003; 228: $15-21$.

95 Brenner DJ, Hall EJ. Computed tomography-an increasing source of radiation exposure. N. Engl. J. Med. 2007; 357: 227784. 